УДК 911.338.485(571.17+571.52)

ПЕРСПЕКТИВЫ РАЗВИТИЯ САКРАЛЬНОГО ТУРИЗМА В КЕМЕРОВСКОЙ ОБЛАСТИ И РЕСПУБЛИКЕ ТЫВА

Елизавета В. Чайкина ${ }^{1,1, ~ *, ~ А л е к с е и ̆ ~ М . ~ В е д е н и н ~}{ }^{1, @ 2, ~ * ~}$

\author{
${ }^{1}$ Кемеровский государственный университет, Россия, 650000, г. Кемерово, ул. Красная, 6 \\ @1 litvinova912@mail.ru \\ @2aleksei.vedenin2013@yandex.ru
}

Поступила в редакичию 30.11.2017. Принята к печати 21.12.2017.

Ключевые слова: сакральный туризм, эзотерический туризм, Кемеровская область, Кузбасс, Республика Тыва, культовые объекты, сакральные места.
Аннотация: В статье рассмотрена возможность развития в Кемеровской области и Республике Тыва сакрального или эзотерического туризма как одного из перспективных направлений туристической отрасли с целью повышения туристской привлекательности регионов и привлечения большего количества российских и зарубежных туристов. Приводится обзор рекреационных ресурсов двух регионов, необходимых для развития данного вида туризма, даётся их характеристика, описывается сакральная значимость для коренных народов Кемеровской области и Республики Тыва. Автор работы приходит к выводу о том, что наличие культовых объектов и уникальная самобытная культура коренных народов регионов определяют условия для развития в них сакрального туризма. Рассматриваются также имеющиеся эзотерические туристические маршруты, функционирующие в пределах Кузбасса и Тывы. Отмечается, что в настоящее время сакральный туризм в Республике Тыва развит на более высоком уровне, чем в Кемеровской области. В заключении приводится перечень необходимых действий для успешного развития сакрального туризма в пределах исследуемых регионов. Прежде всего, акцентируется внимание на взаимодействии представителей туристического бизнеса и коренных народов Кузбасса и Тывы.

Для цитирования: Чайкина Е. В., Веденин А. М. Перспективы развития сакрального туризма в Кемеровской области и Республике Тыва // Вестник Кемеровского государственного университета. Серия: Биологические, технические науки и науки о Земле. 2017. № 4. С. 52-55. DOI: 10.21603/2542-2448-2017-4-52-55.

В настоящее время туризм рассматривается как приоритетная отрасль экономики России в целом, и отдельных её регионов, в частности. В связи с этим многие регионы создают туристские бренды, разрабатывают кластеры и внедряют новые маршруты. Это позволяет им привлечь инвесторов и большое количество российских и зарубежных туристов. Кемеровская область и Республика Тыва не являются исключением.

Кузбасс отличается наличием разнообразных рекреационных ресурсов, но, к сожалению, пока его туристский потенциал развит не в полной мере. В качестве приоритетных видов туризма в регионе выделяются лишь три: горнолыжный, культурно-исторический и спортивный. В территориальном аспекте в большей степени развивается юг Кузбасса - Горная Шория. Наибольшей популярностью среди туристов пользуются зимние виды туризма [1]. Похожая ситуация наблюдается и в Республике Тыва. Она находится в Центре Азии и отличается от других регионов страны первозданной нетронутой природой и самобытной культурой. В данном регионе также существуют трудности с сезонностью туризма, преимущественно он развивается в летний период времени, к наиболее популярным видам отдыха относят пять разновидностей туризма: активный, лечебно-оздоровительный, сельский, этнокультурный и событийный, экологический [2]. В связи с этим необходимо изучение возможных новых и перспективных видов туризма, которые будут востребованы в Кемеровской области и в Республике Тыва в любое время года.

Богатство историко-культурного наследия, благоприятные природные условия, разнообразные рекреационные ресурсы создают основу для развития в пределах данных регионов различных видов туризма, среди которых особая роль принадлежит сакральному или эзотерическому туризму. Эзотерический туризм - новый и перспективный вид туризма, цель которого состоит в том, чтобы открыть значимость жизнедеятельности человека, научить его быть счастливым в настоящем времени [3]. В ходе эзотерических туров участники посещают Места силы - территории,

\footnotetext{
* Исследование выполнено при финансовой поддерэке РФФИ в рамках научных проектов № 17-01-18076 «Этнологическая экспертиза: этносоциальные процессы и новые идентичности «малочисленных» этнических групп Республики Тыва в современном контексте»; № 17-11-42601 «Шорцы Кемеровской области: сакральное пространство культуры малочисленного этноса в контексте геоинформационного исследования факторов земельных конфликтов»; № 16-46-420035 «Коренные малочисленные этносы Кемеровской области под воздействием угольных компаний: социальные и экологические факторы развития конфликтов в районах угледобычи в контексте мирового опыта междисциплинарных исследований и практик управления».
} 
аккумулирующие в себе энергию, которая выходит на поверхность земли и оказывает положительное влияние на физическое, энергетическое и духовное здоровье людей. Путешествия по подобным местам делают возможным наполнение человека энергией, здоровьем, красотой и молодостью. Посредством взаимодействия отдыхающих с культовыми объектами происходит восстановление организма, его психического и творческого потенциалов, раскрывается интуитивное восприятие мира [4].

Кемеровская область и Республика Тыва имеют необходимые рекреационные ресурсы для развития данного вида туризма.

На юге Кузбасса проживают шорцы - коренной малочисленный народ. До сегодняшнего дня они поддерживают свою национальную культуру, быт, традиции, обычаи и верования. Сохранились сведения и о значимых культовых объектах. К ним относятся горы Мустаг, Патын, Каратаг, Айган и др., реки Кондома и Мрассу [5].

Гора Мустаг (Пустаг) - самая высокая точка на территории Горной Шории. Высота горы составляет 1570 м. Пустаг расположена между двух горных систем - Алтаем и Саянами. Гора и примыкающие к ней области сложена гранитными породами. Шорское население назвают Мустаг «ледяной горой», так как она покрыта снегом почти 9 месяцев в году. В народе бытуют легенды о том, что у горы есть грозный хозяин. Для того чтобы умерить его нрав шорцы проводят древний обряд - «шачиг» [6].

Гора Патын находится в центре Горной Шории. Представляет собой уникальный геологический объект геоморфологического и минералогического профиля. Она находится на водоразделе Мрассу и Таштыпа, занимает площадь около

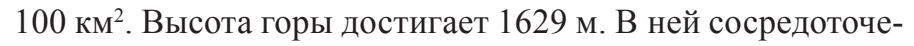
ны большие запасы титаномагнетитовых руд, исчисляемых миллиардами тонн.

Гора Ай-Каан (в современном произношении Айган) находится в глубине Шории, вблизи с. Усть-Анзас, что переводе с шорского языка означает «Хан месяца». Существуют легенды о том, что Хан (покровитель, господин) месяца охраняет данное место. С незапамятных времён местное население наблюдает необъяснимые явления: перед каким-либо несчастьем, поворотными событиями или затяжными ненастными днями на вершине горы появляются зеркальные двери. Гора Айган аномальная, со своенравным характером [7].

Река Мрассу берёт своё начало на Абаканском хребте близ города Мыски, является левым притоком Томи, которая принадлежит к бассейну реки Обь. Мрассу протекает по всей долине Горной Шории, её длина составляет 338 км. Это горная река, отличающаяся бурным характером, извилистым руслом, наличием множества порогов. На побережье Мрассу располагается уникальный Шорский национальный парк.

Река Кондома относится к крупнейшему бассейну реки Обь и является левым притоком реки Томь. Основными притоками Кондомы являются реки: Тельбес, Чулеш, Теш и Мундыбаш. Река имеет протяженность 392 км, исток ее располагается на хребте Бийская Грива (верховье реки), а низовье Кондомы достигает Кузнецкой котловины. Русло реки в верховьях является каменистым, река имеет бурное, неспокойно и ухабистое течение, зато в низовьях течение Кондомы становится более медленным и спокойным. Зимой река полностью замерзает [6].

У шорцев много легенд связано с культовыми объектами. Они верили, что когда-то горы и реки были людьми, а также, что у любой реки есть хозяин. Покровители гор охраняют покой, а жизнь рекам даёт хозяин, и пока он не спустится в воду, они не пойдут [7].

В Республике Тыва располагаются различные культовые объекты и Места силы. Наиболее известными из них являются: горы: Хайыракан, Уттуг-Хая; река Эне-Сай (Енисей), озеро Дус-Холь, а также многочисленные природные целебные воды - аржааны.

Гора Хайыракан - сакральное место, отличающееся колоссальной энергетикой, считающееся обителью духов и культурным достоянием тувинского народа. Гора причисляется к местам шаманской силы. К её подножию ежегодно съезжаются шаманы из разных уголков земли, чтобы зарядиться энергетикой, укрепить и очистить дух. В настоящее время гора является местом паломничества многочисленных туристов.

Гора Уттуг-Хая - священное место на протяжении нескольких веков, по преданиям исполняет любые желания людей [8].

Река Енисей - самая полноводная река России. В прошлом киргизы дали название реке «Эне-сай», что переводится как «мать-река», эвенки называли реку «ионэсси»«большая вода». Данные названия отражают отличительные особенности Енисея. В России река занимает четвёртое место по длине и второе по площади водного бассейна. Енисей отличается бурным и могучим характером, в связи с этим его называют братом океана. Река разделяет Сибирский регион на две части: Западную и Восточную. В Республике Тыва Енисей играет значимую роль в традиционной культуре местного населения. С 2012 года здесь отмечается экологический праздник «День Енисея».

Дус-Холь - солёное озеро Республики Тыва, находится в 45 км от г. Кызыла. Минерализация воды более 80 \% это говорит о том, что озеро является целебным. Водоем питается водами из аржаанов - священных источников и считается средством практически от всех видов болезней. Шаманы перед прохождением обряда посвящения должны обязательно в нём искупаться. Среди местных жителей бытует легенда о том, что если человек остается ночью на берегу озера, то обязательно придут духи источников, чтобы проверить душу гостя: когда она чиста, позволят здесь находиться, нет - прогонят.

Республика Тыва знаменита лечебными источниками аржаанами, которых насчитывается здесь более 150: пресных и солёных. Феномен «аржаанного лечения», являющийся составной частью культуры и традиций тувинского народа с древнейших времен, представляет собой уникальное явление, сохранившееся в масштабном плане на пространстве стран СНГ практически только в Тыве [9].

Кроме того, привлекательность Республики Тыва с точки зрения развития эзотерического туризма определяется уникальным сочетанием традиций шаманизма и буддизма. Шаманы Тывы по сей день практикуют традиционные обряды, проводимые в местах скопления особой энергии. Буддийские храмы привлекают паломников, а также желающих обрести духовное спокойствие [2]. 
Таким образом, наличие культовых объектов и уникальная самобытная культура коренных народов Кемеровской области и Республики Тыва определяют условия для развития здесь сакрального туризма.

В Кузбассе данный вид туризма практически не развит и находится в зачаточном состоянии. Имеются отдельные попытки организации экскурсий к культовым объектам, в ходе которых упоминается об их истории, легендах и сказаниях. Однако они носят чисто информативный характер, в местах силы не проводятся культурные практики по восстановлению и пополнению духовных и энергетических сил человека. В Республике Тыва некоторыми туроператорами уже организуются эзотерические туры. Например, туристическая компания «Белые дороги» проводит такие туры как «Загадки Тывы. Путешествия по Местам силы», «Под Хрустальным куполом Тывы»; туроператор по Сибири «Саянское кольцо» - эзотерический тур-семинар «Посвящение в шаманизм» $[9 ; 10]$. В перечисленных турах принимают участие потомственные шаманы, которые проводят различные обрядовые действия в зависимости от потребностей отдыхающих. Таким образом, на сегодняшний день сакральный туризм в Республике Тыва развит в большей степени, чем в Кемеровской области. Данный факт объясняется высокой сохранностью культурно-исторических знаний и практик коренных народов, которые поддерживаются в современном жизненном укладе, а также спросом со стороны туристов на отдых, целью которого является восстановление физических, духовных и энергетических сил.

Для полноценного и масштабного развития сакрального туризма в пределах данных территорий, научного обоснования уникальных свойств культовых объектов и достоверной информации об истории их образования, обрядах, легендах, сказаниях, а также уровня значимости для шорцев и тувинцев необходимо привлечение научных специалистов и представителей коренного населения. Важно проведение социологических опросов местных жителей для определения их заинтересованности в появлении туристического бизнеса в местах их компактного проживания. Также эзотерический туризм требует развития инфраструктуры, коллективных средств размещения, мест общественного питания и т. д.

После чего на юге Кемеровской области и в Республике Тыва могут разрабатываться и внедряться сакральные туристические маршруты, в ходе которых туристы будут узнавать о результатах научных исследований, аномальных и необычных явлениях, связанных с культовыми объектами коренного населения. Преимущество сакрального туризма заключается ещё и в том, что его развитие не требует больших инвестиционных затрат, он может развиваться круглогодично, как правило, прохождение туристических маршрутов не требует специальной физической подготовки, а потому подходит практически для всех возрастов и категорий населения - от студентов до людей преклонного возраста.

\section{Литература}

1. Туризм в Кузбассе. Режим доступа: http://www.ako.ru/Socsfera/turizm.asp?n=8 (дата обращения: 31.08 .2017 ).

2. Туризм Республики Тыва. Режим доступа: http://www.mert.tuva.ru/directions/tourism/ (дата обращения: 18.09.2017).

3. Мельникова Е. Е. Культовые объекты в Алтайском крае и Республике Алтай и их использование для развития сакрального туризма // География, история и геоэкология на службе науки и инновации: материалы Международной научно-практической конференции, 22-23 апр. 2011. Красноярск, 2011. С. 134-135.

4. Эзотерический туризм. Режим доступа: http://www.natali-trevel.ru/esoteric-tour/ (дата обращения: 03.09.2017).

5. Чайкина Е. В. Шорцы Кемеровской области: перспективы сохранения традиционной культуры через механизмы развития этнографического туризма // Малочисленные этносы в пространстве доминирующего общества: практика прикладных исследований и эффективные инструменты этнической политики: материалы всероссийской с международным участием научно-практической конференции (г. Кемерово, 17-18 окт. 2014 г.). Кемерово, 2014. С. 537-539.

6. Информационный портал «По-Сибири»: Кемеровская область. Режим доступа: http://posibiri.ru/category/кемеровская-область/ (дата обращения: 05.09.2017).

7. Заповедные места Кузбасса. Режим доступа: http://nk-tv.com/125365.html (дата обращения: 10.01.2017).

8. Республика Тыва. Режим доступа: http://vladimir.nosov.org/category/tyva (дата обращения: 07.09.2017)

9. Туры по Сибири. Режим доступа: http://www.sayanring.ru/tour/browse/page/1/type/32/region/6 (дата обращения: 17.09.2017).

10. Эзотерические туры. Режим доступа: http://tuvatravel.ru/ezotericheskie/ (дата обращения: 11.09.2017). 


\title{
PROSPECTS FOR DEVELOPMENT OF SACRAL TOURISM IN KEMEROVO REGION AND THE REPUBLIC OF TUVA \\ Elizaveta V.Chaikina, ${ }^{1,1, ~ *, ~ A l e k s e y ~ M . ~ V e d e n i n, ~ @ 2, ~ * ~}$
}

\author{
${ }^{1}$ Kemerovo State University, 6, Krasnaya St., Kemerovo, Russia, 650000 \\ @1litvinova912@mail.ru \\ @2aleksei.vedenin2013@yandex.ru
}

Received 30.11.2017. Accepted 21.12.2017.

Keywords: sacred tourism, esoteric tourism, Kemerovo region, Kuzbass, Republic of Tyva, cult objects, sacred places.

\begin{abstract}
The paper considers a number of issues linked with the possibilities for the development of sacral (or esoteric) tourism in the Kemerovo Region and the Republic of Tuva as most promising areas from the point of view of tourist industry. The authors assess the sacral tourism development as a way to attract more domestic and foreign tourist into the regions and review their recreational resources as well. The paper shows the significance of sacral tourism resources for indigenous communities in the Kemerovo region and the Republic of Tuva. As one of main conclusions in this regard, the authors state that presence of cult objects and unique indigenous culture in the regions shape key conditions needed for sacral tourism development. The research includes the existing esoteric tourist routes operating within both regions: the analysis has revealed that the sacral tourism in the Republic of Tuva has a higher level of development than that of the Kemerovo region. The final part of the paper offers a list of actions necessary for successful development of sacral tourism within the regions. The authors' attention is mostly focused on the interaction between the tourism business representatives and the indigenous communities.
\end{abstract}

For citation: Chaikina E. V., Vedenin A. M. Perspektivy razvitiia sakral'nogo turizma v Kemerovskoi oblasti i respublike Tyve [Prospects for Development of Sacral Tourism in Kemerovo Region and the Republic of Tuva]. Bulletin of Kemerovo State University. Series: Biological, Engineering and Earth Sciences, no. 4 (2017): 52-55. DOI: 10.21603/2542-2448-2017-4-52-55.

\section{References}

1. Turizm v Kuzbasse [Tourism in Kuzbass]. Available at: http://www.ako.ru/Socsfera/turizm.asp?n=8 (accessed 31.08.2017).

2. Turizm Respubliki Tyva [Tourism of the Republic of Tuva]. Available at: http://www.mert.tuva.ru/directions/tourism/ (accessed 18.09.2017).

3. Melnikova E. E. Kul'tovye ob»ekty v Altayskom krae i Respublike Altay i ikh ispol'zovanie dlya razvitiya sakral'nogo turizma [Religious objects in the Altai Territory and the Altai Republic and their use for the development of sacral tourism]. Geografia, istoriia i geoekologiia na sluzhbe nauki i innovatsii: materialy Mezhdunarodnoi nauchno-prakticheskoi konferentsii, 22-23 aprelia 2011 [Geography, history and geoecology at the service of science and innovation: materials of the International Scientific and Practical Conference, April 22-23, 2011]. Krasnoyarsk, 2011, 134-135.

4. Ezotericheskii turizm [Esoteric tourism]. Available at: http://www.natali-trevel.ru/esoteric-tour/ (accessed 03.09.2017).

5. Chaikina E. V. Shortsy Kemerovskoi oblasti: perspektivy sokhraneniia traditsionnoi kul'tury cherez mekhanizmy razvitiia etnograficheskogo turizma [The Shors of the Kemerovo region: perspectives of preserving traditional culture through mechanisms of development of ethnographic tourism]. Malochislennye etnosy v prostranstve dominiruiushchego obshchestva: praktika prikladnykh issledovanii i effektivnye instrumenty etnicheskoi politiki: materialy vserossiiskoi s mezhdunarodnym uchastiem nauchno-prakticheskoi konferentsii (g. Kemerovo, 17-18 okt. $2014 \mathrm{~g}$.) [Small ethnic groups in the space of the dominant society: the practice of applied research and effective tools of ethnic policy: the materials of the All-Russian with the international participation of the scientific and practical conference (Kemerovo, October 17-18, 2014)]. Kemerovo, $2014,537-539$.

6. Informatsionnyi portal «Po-Sibiri»: Kemerovskaia oblast [Informational portal «Po-Siberia»: Kemerovo region]. Available at: http://posibiri.ru/category/кемеровская-область/ (accessed 05.09.2017).

7. Zapovednye mesta Kuzbassa [Reserves of Kuzbass]. Available at: http://nk-tv.com/125365.html (accessed 10.01.2017).

8. Respublika Tyva [Tyva Republic]. Available at: http://vladimir.nosov.org/category/tyva (accessed 25.08.2017).

9. Tury po Sibiri [Tours in Siberia]. Available at: http://www.sayanring.ru/tour/browse/page/1/type/32/region/6 (accessed 17.09.2017).

10. Ezotericheskie tury [Esoteric tours]. Available at: http://tuvatravel.ru/ezotericheskie/ (accessed 11.09.2017).

\footnotetext{
* This research was supported by the Russian Foundation for Basic Research within the framework of the following research projects: (1) No. 17-01-18076 "Ethnologic Expert Assessment: Ethnic and Social Processes in Tuva Republic and Small-Numerous Ethnic Groups' New Identities in Contemporary Perspective”; (2) No. 17-11-42601 “The Shor People of Kemerovo Region: Small-Numerous Ethnic Group's Space of Sacred Culture in the Perspective of GIS-Based Research of Land-Use Conflicts"; (3) No. 16-46-420035 "Indigenous Peoples of Kemerovo Region Under the Pressure from Coal-Mining Companies: Societal and Environmental Roots of Conflicts Escalation in the Mining Territories in Context of World's Interdisciplinary Research \& Management Experience.
} 